\title{
A UNIVERSIDADE NO BRASIL E POLÍTICAS DE AÇÕES AFIRMATIVAS
}

\author{
Paulo Gomes Lima ${ }^{1}$ \\ Universidade Federal da Grande Dourados [UFGD]
}

\section{RESUMO}

Esse trabalho analisa a universidade no Brasil no contexto do modo-de-produção capitalista a partir das políticas de ações afirmativas e sua projeção ideológica na contenção do acesso e democratização às classes sociais menos favorecidas. Apresenta os condicionantes sócio-históricos de tais políticas e a incorporação de cotas como instrumentos de acesso ao ensino superior, a exemplo do que faz os EUA, evidenciando os pontos de inflexão ideológica, orientados pela ratificação ao discurso hegemônico e à acomodação da lógica do processo produtivo do capital, portanto, trata-se de uma pesquisa exploratória por meio de revisão de literatura especializada, que discute a centralidade das políticas de inclusão social à universidade no Brasil e conclui que é necessária a superação das práticas dissimuladoras na centralidade capital-trabalho; pela ação comunicacional entre direito e democracia.

Palavras-chave: políticas de inclusão social; universidade brasileira; ações afirmativas

\section{UNIVERSITY IN BRAZIL AND AFFIRMATIVE ACTION'S POLICIES}

\begin{abstract}
This work analyses the University in Brazil in the context of the mode of capitalist production from affirmative action's policies and its ideological contention access and democratization at disadvantaged social classes. Presents the socio-historical factors such policies and the incorporation of quotas as instruments of access to higher education, as does the USA, underlining the ideological inflection points, driven by ratifying the hegemonic discourse and accommodation of productive process logic of capital, so this is an exploratory search via literature review, which discusses the centrality of social inclusion policies to the University in Brazil and concludes that it is necessary to overcome dissimulator's practices on centrality work capital; by communicational action between law and democracy.
\end{abstract}

Keywords: social inclusion policies; affirmative action's policies; Brazilian University

\section{Introdução}

As políticas de ações afirmativas têm sido entendidas como meio de beneficiar grupos socialmente desfavorecidos e ou discriminados na consecução de recursos em distintos setores sociais, inclusive na universidade por meio de cotas e outros projetos de índoles compensatórias. Essa efervescência ganha notório escopo no final da década de 1990 e primeira década do século XXI quando encontros específicos em nível mundial, promovidos pela UNESCO $(1998,2009)$ e outros organismos multilaterais colocam na pauta de discussão a busca pela solidarização mundial por meio de ações indutivas de inclusão social. 
Entretanto, como mostra a história, a partir de então muito mais do que uma razão de atendimento social das demandas de agrupamentos humanos desfavorecidos ou discriminados, as políticas de ações afirmativas tem se caracterizado como uma das faces da reorganização do metabolismo do capital que certamente não se encerra com a projeção de cotas à universidade, dada a expressiva dimensão do processo histórico de exclusão social e a exploração selvagem do trabalhador que retroalimentam a estrutura de poder na relação explícito-implícito.

O explícito trata das interfaces oficiais das políticas e legislações para a sociedade pretendendo-se, em tese, a horizontalização indistinta das oportunizações sociais aos cidadãos, especificamente aos bens e serviços que os grupos das classes menos favorecidas historicamente não tiveram acesso. O implícito, o não dito, também considerado como "currículo oculto da engrenagem sociometabólica" funciona como reafirmação da estrutura imobilista da teoria social capitalista que, numa pele de cordeiro, não leva em conta qualquer possibilidade de romper com o lobo que trás em seu seio.

Propõe-se justiça social em nível ideal, mas não se promove a sua socialização em sentido amplo e universal da materialidade, muito embora o discurso oriente a sua contemplação por meio de políticas públicas compensatórias. Legitima-se a universalização da educação básica pelo consentimento às orientações de organismos multilaterais, mas não se rompe com as desigualdades sociais, além de se constatar o registro de índices alarmantes de baixa qualidade do ensino no Brasil e no mundo periférico, pois tais organismos partem de um pressuposto utópico de igualdade e equidade: legal, mas não de fato - como se vê pela indução aos processos de inclusão social ao invés da não-exclusão.

Essa lógica do reforçamento do ideário capitalista, no núcleo das políticas públicas para a educação no Brasil, tem cumprido suas metas, os resultados são explicitados inclusive no baixo alcance das scores estabelecidas do PNE (Plano Nacional de Educação) 2001-2010, enquanto isso outros PNEs são projetados para se conformar o cumprimento daquelas que "ainda" não foram alcançadas e de forma enfática, por meio de políticas de contenção, especiais, temporárias ou mais comumente como proferem os organismos multilaterais, pelo processo de solidarização induzida pela inclusão social.

As ações afirmativas não fogem a essa lógica em sua dimensão explícita de inclusão social à universidade brasileira apelando ao estado de preocupações supra-ideológicas humanizadas pelo capital e, como se não bastasse, tendo como referencial o "modelo" norte-americano na inserção inicial de negros e depois, tentando encampar uma dimensão mais pluralista, estende também a outros grupos (indígenas e portadores de necessidades especiais) e paulatinamente consente-se que "alguns" alunos de escolas públicas possam ter o seu percentual de vagas.

Observa-se, de forma concreta, o processo de velamento por meio da contenção e controle do acesso à educação superior, ao invés de sua universalização e democratização ao longo do tempo, além do que, a solidarização anunciada ampara-se num entendimento conveniente de humanização, ou seja, aquela que se destina a conceder benfeitorias pontuais, inversamente ao processo de horizontalização de direitos, desvirtuando o olhar, isto é, alienando os atores sociais na imposição simbólica e material do ideário da "nova solidarização de mercado" induzindo a aquiescência naturalizada que não causa qualquer mácula na estrutura hegemônica do controle social do capital.

Esse trabalho analisa a universidade no Brasil no contexto do modo-de-produção capitalista problematizando as políticas de ações afirmativas e sua projeção ideológica na contenção do acesso e democratização às classes sociais menos favorecidas. Apresenta os condicionantes sócio-históricos de tais políticas e a incorporação de cotas como 
instrumentos de acesso ao ensino superior, a exemplo do que faz os EUA, evidenciando os pontos de inflexão ideológica, orientados pela ratificação ao discurso hegemônico e à acomodação da lógica do processo produtivo do capital.

A democratização à universidade por meio das políticas de ações afirmativas como correção da dívida histórica do Brasil para compensar a exclusão e privação social de direitos, caracteriza-se como elemento ideológico em sentido restrito na dimensão do arranjo do sociometabolismo do capital e, portanto, como democratização e universalização aparentes, visto que, permitidas entre os eixos do "consenso" e "consentimento", isto é, pelo convencimento ideológico e sua naturalização, como único caminho na dimensão atual da história.

Sob um olhar recorrente, de cunho dialético, identificou-se pontos de inflexão ratificadores de interesses do capital e, por outro lado, contrapontos como objeto de denúncia ao processo de expropriação histórica à educação superior no Brasil. A sedimentação do conceito de justiça social aplicada a democratização do acesso à universidade por meio de políticas públicas compensatórias, embora tenha sido a perspectiva predominante na última década do século $\mathrm{XX}$ e reelaborada na primeira década do século XXI, traz elementos suficientes para se entender que o próprio conceito é objeto de redução para a lógica que estrutura o arranjo capitalista - "a justiça funcional", retroalimentada pelas contradições do poderio econômico e ideológico.

Para que se problematize o desdobramento desse itinerário e a ideologia que se materializa nos projetos sociais das políticas públicas para a educação superior brasileira, destaca-se no texto três pontos de discussão, recortando as ações afirmativas como eixos de recorrência a partir de seu surgimento nos EUA (Estados Unidos), bem como o seu processo de constituição e implicações para a realidade brasileira.

O método de exposição do texto tem como objetivo, analisar alguns pontos de inflexão do processo de democratização e universalização à universidade brasileira no seio do arranjo dos interesses do capital. Decorrente dessa direção o artigo foi organizado em três seções: 1) Universidade no Brasil e políticas públicas de educação: condicionantes sócio-históricos na contemporaneidade, 2) ações afirmativas como pontos de correção de dívida histórica, 3) ações afirmativas para a universidade: contrapontos acerca da discriminação positiva e, num segundo momento a reflexão sobre ou encaminhamentos para se pensar uma universidade democrática, universal e humana na realidade brasileira.

\section{Universidade no Brasil e políticas públicas de educação: condicionantes sócio- históricos na contemporaneidade}

Com o fim do período militar e o processo de redemocratização no Brasil, muitos movimentos sociais começaram a se mobilizar em busca das correções de dívidas sociais historicamente situadas, principalmente entre 1989 e a década de 1990, período em que o metabolismo capitalista em suas múltiplas faces difundia o discurso de oportunidades e equidade sociais e "convertia" um número cada vez mais expressivo de vozes à melodia de políticas públicas inclusivas, negando, por meio de justificativas veladas, a sua universalização.

Piovesan (2006) enfatizou que quando o Supremo Tribunal de Justiça brasileiro avaliou que a Constituição de 1988 respaldava o estabelecimento de cotas para grupos desfavorecidos, justificando a sua oferta e desenvolvimento em todos os Estados da Federação, legitimou-se a construção de uma justiça social destinada aos marginalizados por meio desse instrumento. Entretanto, o que ocorreu de fato, foi um estrangulamento ou 
reducionismo da compreensão da justiça social em si, que não se coaduna com a determinação jurídica de qualquer outorga ou consentimento de abertura na forma da lei, estabelecendo raios de alcances, isto é, definindo critérios de inserção e não de universalização das oportunidades sociais e muito menos educacionais.

A justiça social nesse sentido é descaracterizada em sua profundidade, pautando-se como uma justiça formalizada pela lógica da solidarização mercantilizada e excludente, apropriada ao controle social de conformação capitalista, isto é, por um lado, definem-se legalmente os parâmetros de justiça e direitos indistintos, por outro lado, a totalidade de sua assunção é controlada de forma restritiva, porque classifica o seu alcance em critérios descompassados, reduzindo a sua dimensão estrutural numa cidadania de reconhecimento percentual - o quanto e quem é cidadão de direito de 20, 25, 30 ou 35\% e assim por diante.

Portanto, a cidadania num processo amplo de abertura [não supranacional, mas desnacionalizado (JESSOP, 1998)], projeta a inclusão social das classes desfavorecidas como preocupação ímpar do capital, mas não se pode deixar de observar que tal quadro fora objeto do ideário neoliberal na expansão de mercado por meio da elevação simbólica do poder aquisitivo dos cidadãos nos anos de 1990 (avançando consideravelmente nos primeiros anos do século XXI), "educando-os" para a permanência da aceitação tácita centrada na policompetência da divisão social do trabalho, de forma especial nos países de economias emergentes no cenário mundial, como o caso do Brasil, enquanto que aqueles países notadamente mais periféricos e pobres eram assistidos por auxílios diversos na orientação de suas políticas sociais, dentre as quais para a alimentação, transporte, saúde e educação, de forma controlada, apresentando visibilidade suficiente para a atestação do "papel de responsabilização do capital no atendimento às necessidades dos que sofrem" qualquer tipo de privação no mundo dos homens, ratificando ideologicamente a necessidade e atualidade de sua teoria social.

As políticas públicas no Brasil, nessa direção, veiculam o anúncio de que o Estado ampara, têm um projeto definido de formação para a cidadania e que o seu planejamento democrático para a universalização e humanização é possível com estratégias diferenciadas de atendimento, à medida que discrimina positivamente grupos sociais, entretanto, sem qualquer intenção de ruptura com seus arranjos de exclusão, isto é, o sociometabolismo permanece o mesmo, ao tempo em que são apresentados desvios que alienam cada vez mais o homem do papel de autoprodutor de sua existência.

A idéia de responsabilização ou accontability amplamente enraizada nos países hegemônicos é ampliada e expandida aos demais países com características voltadas para a diminuição do Estado, esse por sua vez, centraliza a sua versão de qualidade para o ensino fundamental, diminuindo os investimentos na educação infantil e ensino superior invertendo a responsabilidade de atendimento para a iniciativa privada e/ou sob a mobilização da sociedade que, em última instância, será assessorada por aquela. Esse fenômeno não explica a reversão de políticas do Estado capitalista no sentido de sua superação, mas ratifica a dimensão que atende o sociometabolismo capital na qualificação de uma tipologia de trabalhador, na manutenção de sua estrutura.

As políticas públicas para a educação, encampadas por essa direção encontram terreno fértil no Brasil desonerando o Estado de sua responsividade legal quanto ao atendimento dos interesses da população, exemplo disso foi à proposição da Emenda Constitucional $\mathrm{n}^{\circ} .19$ de 04 junho de 1998, quando da reforma do Estado, que estabelecia parâmetros restritivos ao seu crescimento, ao mesmo tempo em que inseria em nível conceitual e factual o termo "público não-estatal", favorecendo e incentivando as parcerias público-privadas, porque entendidas como de interesse público, assim a "revolução 
gerenciada" assumiu a "necessidade de transferência" das competências do Estado para a iniciativa privada.

Os ventos do neoliberalismo encontraram guarida nesse período, o que foi continuado depois na segunda gestão do governo FHC e também nas duas gestões do governo de Luis Inácio Lula da Silva. Iniciadas oficialmente na década de 1990 as ações afirmativas seguiriam essa direção, numa aparência de justiça social, mas com o foco na desmobilização dos movimentos reivindicatórios e alargando a transferência de verbas para as instituições privadas de educação superior por meio de programas assistencialistas.

\section{Ações afirmativas para a universidade: pontos de correção de dívida histórica?}

Em meio à construção da problemática não nos parecia coerente simplesmente nos colocar contra ou a favor da principal discussão do dia: ações afirmativas encampadas por políticas de cotas na universidade brasileira; nem mesmo nos manter omissos e passivos diante de um momento histórico que solicitava recorrências norteadas por um olhar crítico-reflexivo, dessa maneira assumir-se-á a orientação de problematizarmos as condições em que se propunham tais ideários no seio de uma sociedade capitalista, estruturada na metáfora do manobrista de ferrovias de Weber ${ }^{2}$.

Em pleno governo FHC, em 1996, ano da inauguração da LDB 9394/96, fora constituído um Grupo de Trabalho Interministerial para a Valorização da População Negra, que como orientação definia "ações afirmativas" como "[...] medidas especiais e temporárias, tomadas pelo Estado [...] com o objetivo de eliminar desigualdades historicamente acumuladas, garantindo a igualdade de oportunidade e tratamento, bem como de compensar perdas provocadas pela discriminação e marginalização, por motivos raciais, étnicos, religiosos, de gênero e outros" (BRASIL, 1996, p.10).

O amplo espectro marcado pelas intervenções neoliberais do governo de então denunciavam o percurso de suas "concessões" ou "aberturas consentidas" e nomeadas de "medidas especiais e temporárias", que não se firmavam como conquista histórica do povo brasileiro, principalmente no tocante ao ingresso à universidade, mas "tomadas pelo Estado", para que por meio de deliberações fossem eliminadas as desigualdades sociais historicamente acumuladas. Propunha-se uma correção da dívida histórica, a exemplo dos EUA, com os grupos e classes sociais marginalizados por meio da "inclusão social", inicialmente voltada ao atendimento de frações da população negra no Brasil, estendida, a posteriori, aos indígenas e pobres.

Nesse projeto não havia espaço para se articular outro olhar ou arranjo social em que não houvesse excluídos, mas o panorama era o de, mantendo-se o projeto histórico da universidade para poucos no Brasil, as medidas inclusivas, a exemplo do modelo norteamericano, por meio das ações afirmativas, atenuariam as questões situadas pelos movimentos sociais. É interessante observar que essa naturalização do referido modelo na realidade brasileira não se enfocava as resistências dentro do próprio Estado americano, pautado pela segregação racial e econômica e ao mesmo tempo pela desmobilização dos desafetos sociais explícitos por organizações situadas.

Entre a concessão de ações afirmativas e o histórico de meritocracia, historicamente na universidade americana aconteceram muitos posicionamentos contrários, mas as conformações em nome do "controle social" governamental e de mercado consentiram um arranjo de "igualdade" não somente quanto ao acesso às oportunidades de trabalho, também à prospecção percentual de agrupamentos humanos ao ensino superior, ao invés de tratamento indistinto de classes sociais, raça e gênero. 
Nesse quadro as ações afirmativas foram propostas com o cuidado de não evidenciar os interesses e arranjos capitalistas de forma explícita, daí o incentivo governamental estendido, inclusive, à própria universidade na ênfase de discussões que geraram posicionamentos contrários ou favoráveis à temática, entretanto, a história mostra isso amplamente, independentemente de qualquer direcionamento, os interesses neoliberais não seriam abalados, apenas tiveram o seu foco desviado convenientemente, negando os pressupostos neoliberais de um lado e ratificando medidas para a sua conservação no entrelaçamento Capital+Trabalho+Estado ${ }^{3}$.

A proposição de uma sociedade e uma educação universalizante, humanizante e democratizante em si, somente é pauta de discussão em nível de projeção ideal no sistema teórico capitalista, enquanto for instrumento de conservação de suas estruturas. Não há esforço para qualquer rompimento da expropriação do homem pelo capital e a construção de uma teoria social capaz da superação da luta de classes nessa perspectiva. Embora se tenha em mente que as políticas públicas, particularmente as de educação, têm a incumbência de reunir todos os segmentos sociais para a elaboração do que se pretende na totalidade social e isso até acontece, até determinado ponto, não ocorre efetivamente a materialização de direitos comuns, o acesso à educação de qualidade, a condição de espaços de universalização, por exemplo, quando a educação superior é colocada em pauta, particularmente quando se trata das meninas dos olhos das classes hegemônicas (medicina, direito, engenharias) e assim o que resta é o fenômeno da culpabilização do sujeito, afinal o sistema (capitalista) humanizou todos os instrumentos possíveis para o acesso aos bens universais, disponibilizou políticas, mas não houve a necessária devolutiva dos segmentos ou "interesse" para "ocupar" o seu espaço no arranjo solidariamente tecido.

A não assunção do enfoque neoliberal, pois como é sabido, prefigura o controle e privilégio do capital, é objeto de orientação do próprio metabolismo capitalista, justificando medidas de controle e chamando a uma participação consentida (sem, no entanto, anunciar ou promover um chamamento para a conscientização das intencionalidades desse itinerário) a sociedade como legitimação do que pode e deve ser feito no quadro econômico mundial, levando-se em conta a responsabilização do social. Sob esse aspecto difundem-se, de forma parcimoniosa, as concessões como totalidades, "naturalizando-as" como único caminho possível de democratização e circunscrevendo o sentido da justiça social à uma superficialidade que se quer. E o que é mais impactante é que a possibilidade de um terceiro olhar nem sequer é considerada.

Articulada ao combate das discriminações e processos de exclusão, nesse caso, as políticas compensatórias são defendidas por alguns, como estratégias essenciais para a inclusão de grupos sociais vulneráveis aos espaços sociais. Por exemplo, Piovesan (2005, p.49) é da opinião de que:

As ações afirmativas, como políticas compensatórias adotadas para aliviar e remediar as condições resultantes de um passado de discriminação cumprem uma finalidade pública decisiva para o projeto democrático: assegurar a diversidade e a pluralidade social. Constituem medidas concretas que viabilizam o direito à igualdade, com a crença de que a igualdade deve moldar-se no respeito à diferença e à diversidade. Por meio delas transita-se da igualdade formal para a igualdade material e substantiva.

Há que se recordar que as políticas de ações afirmativas surgem no bojo dessas discussões nos EUA, como respostas à denúncia da discriminação racial aos negros. No governo de Franklin Roosevelt (1941) é proibida a discriminação racial na contratação de 
funcionários do governo. A denominação "ação afirmativa" foi utilizada pela primeira vez em 1961 pelo presidente John F. Kennedy, quando da instalação da "Comissão por Oportunidades de Emprego". Em 1964, enquanto no Brasil eclode a ditadura militar, nos EUA, Lyndon Johnson estende a proibição de discriminação racial contra a população negra na iniciativa privada por meio da Lei dos Direitos Civis.

Somente em anos posteriores (Décadas de 1960/70) tal nomenclatura viria a ser incorporada à vida política norte-americana no governo de Richard Nixon em 1972, curiosamente, quando da transição dos modelos produtivos para sua reestruturação e quando líderes como Martin Luther King defendia a necessidade de direitos civis dos negros, nesse caso, pretendia-se não somente a inserção da igualdade entre indivíduos, mas a melhoria das condições materiais das minorias raciais e das mulheres, agregando-os ao exército de consumidores em potencial.

A idéia implícita da determinação de Nixon era o de "estabelecimento de metas e prazos específicos" para a inserção da demanda identificada em todas as relações de produção americana e não o de cotas em si, uma vez que o termo "cota" evocava a destinação de um percentual definido para um segmento social, ferindo a natureza da constituição. Embora essa fosse a diretriz assumida, no âmbito concreto, as cotas eram de fato estabelecidas, dito de outra maneira, as "políticas implícitas" para as chamadas ações afirmativas nos EUA norteavam os percentuais de oportunidades sociais, delimitando-as segundo a divisão social de classes e do trabalho.

E a universidade americana se comprometeu com essa lógica até no sentido da justificativa de um núcleo universitário em separado para afro-americanos e latinos, a exemplo do que se vivenciava acerca de igrejas de mesma confissão, atendendo os cidadãos americanos conforme sua raça. Não se tratava do reconhecimento tácito da universalização dos direitos do homem sem distinção, mesmo aferindo um discurso para essa finalidade, contudo, uma "concessão" de oportunidades consideradas pelos conflitos sociais e anuência do capital quanto aos interesses de expansão de mão de obra e mercado consumidor.

Acima do preceito de igualdade entre os homens, muito embora fosse esse o elemento norteador, as ações afirmativas respondem à demanda capitalista dos novos arranjos do mercado: mão de obra, consumidores e expansão de novos nichos consumidores. A correção de uma dívida histórica não pressupõe a inauguração de outra ou a continuação de processos discriminatórios metamorfoseados de ações limítrofes, exige postura comprometida com a transformação social, requisito que o capital afirma assumir, entretanto entre os discursos e as ações há um descomunal hiato, reforçado por contrapontos ideológicos da teoria social do neoliberalismo.

Os mecanismos democráticos favoráveis à regulação do mercado delineiam o perfil do contingente populacional necessário às demandas do consumo sofisticado em nível global, dogmatizando suas premissas por meio de aportes de organismos multilaterais que influi fortemente nas políticas públicas dos países em desenvolvimento. Dessa forma, como afirma Filgueiras (1997, p.29) “[...] homogeneiza-se econômica, política e socialmente parte significativa do planeta, mas, ao mesmo tempo, aprofunda-se a diferenciação no interior de cada espaço nacional, mesmo nos países mais desenvolvidos. Nessa medida, globaliza-se o desemprego e a exclusão social [...]”.

A contraposição do sistema capitalista será a afirmação da derrubada dos muros ideológicos e a socialização dos interesses comuns entre os homens, justificando as medidas pontuais em distintos âmbitos das políticas públicas sem o alcance e o aprofundamento da universalização da justiça social. 
A promessa de inclusão social por meio de ações afirmativas, embora defendida por inúmeros acadêmicos, visto o número crescente de universidades públicas que aderiram ao seu norteamento por uma indutividade ideológica gera mal-estar e desmobiliza movimentos sociais comprometidos com a superação das desigualdades que não basta ser uma aspiração ou dispositivo legal, como observou Hobsbawn (1991, p.261) quando de sua crítica ao neoliberalismo, a luta pela destruição ou rompimento definitivo com os preceitos neoliberais deve constituir-se numa tarefa universalizadora, isto é, “[...] para todas as pessoas que se importam com as tradições e as convenções de lei e civilidade, de liberdade e [...] de responsabilidade e valores sociais, que agora estão sendo gradualmente estrangulados."

A correção de dívida histórica não pressupõe a manutenção das desigualdades ad infinitum, como a política neoliberal pretende, mesmo que seu discurso seja o de negação desse caminho, antes desaliena e aponta a universalização não simplesmente com a inclusão de alguns, mas como a naturalização do direito à democratização e à humanização de todos. Por isso o caráter contraditório tanto na proposição, quanto na efetivação de justiça social circunscrita, o que de fato, não é justiça social.

A graduação do estrangulamento e o caráter ideológico do neoliberalismo produzem um estado de letargia e convencimento, diluindo as tensões dos movimentos reivindicatórios por conta da proposição de uma sintonia dos interesses humanos e quebra dos limites das oportunizações sociais parecendo válidas e suficientes frente à exigência do próprio mercado.

As instâncias ideológicas em sentido restrito estão presentes de forma enfática na universidade brasileira encabeçadas por acadêmicos que se omitem da crítica a essa situação e, como se não bastasse empreendem estudos para analisar o grau de sucesso ou experiências exitosas a partir do modelo neoliberal, corroborando para a manutenção dos arranjos político e social, como avanço que deve ser continuado. Observa-se que o conjunto ideológico da classe dominante não encontra qualquer resistência para a generalização de medidas necessárias, urgentes e que nenhuma outra alternativa se mostra mais coerente ou mais propícia para a sua implementação, uma vez que, "supostamente" comporta os anseios dos grupos dominados.

A nova divisão social do trabalho compassada pela estruturação do capital tem delineado o projeto de universidade para o atendimento de seus interesses, bem como a de educação em geral, a partir dos níveis mais elementares, daí a verificação da ênfase nos investimentos do Ensino Fundamental via fundos específicos (FUNDEF) e, depois expandidos para toda a educação básica (FUNDEB), preparando culturalmente os novos contingentes populacionais para a naturalização do metabolismo do capital. Assim, a lógica subjacente é a de que, se foi possível a universalização da educação básica no modelo capitalista, também o mesmo se aplica à educação superior. Não objeto desse artigo, mas, poder-se-ia questionar que "qualidade de educação básica temos efetivamente no Brasil?"; "que níveis de satisfação tem os pais, alunos e professores?" "Essa 'universalização' tem de fato promovido a inserção e oportunização social que projeta o capital por meio de ações pontuais ?" Nessa direção, a idéia de uma universidade para todos no sentido literal, levando em conta o caso brasileiro e sob o arranjo capitalista, está longe de se constituir uma realidade concreta.

No sistema capitalista, qualquer "ação afirmativa" constituir-se-á num elemento paliativo e remediativo em que os grupos desfavorecidos continuarão condicionados por um processo de expropriação velada, uma vez que, como Kurz (1993, p.233 - colchetes nossos) afirma, trata-se de "[...] um sistema louco e perigoso para humanidade [que] não será abandonado voluntariamente por seus representantes [...]" a menos que haja um 
despertamento e mobilizações sociais significativas e suficientes para a reversão de sua estrutura.

\section{Ações afirmativas para a universidade: pontos e contrapontos acerca da discriminação positiva}

Apenas a exigência do reconhecimento das desigualdades sociais, econômicas, culturais é suficiente para a realização da igualdade? Em si não, mas é um importante indicador para se refletir a necessidade de mudanças estruturais numa sociedade antagônica como a capitalista, talvez o tempo de que dispomos não seja suficiente para se observar o avanço dessas discussões e nem mesmo os encaminhamentos para as mesmas, daí a necessidade de inferir sobre os arranjos estruturais que impedem ou obstaculizam a sua materialização. Outros elementos que não os remediativos (pois não têm o propósito de erradicação das desigualdades sociais e universalização de direitos em sentido amplo) poderão favorecer uma resposta em nível amplo e abrangente. Porém, antes de apresentálos é necessário contextualizarmos as ações afirmativas como "discriminação positiva", e através dessa, a pretensão de se dar por resolvido o encaminhamento das desigualdades sociais.

Em 1965 as Nações Unidas aprovam a Convenção sobre a Eliminação de Todas as Formas de Discriminação Racial, da qual o Brasil passou a ser signatário desde 1968.

Nessa Convenção (no artigo $1^{\circ}$, parágrafo $4^{\circ}$ ) foi estabelecido que "medidas especiais e temporárias" fossem adotadas para proteção, incentivo, equiparação de grupos sociais menos favorecidos às mesmas oportunidades que os grupos socialmente favorecidos. Tais medidas foram denominadas de "discriminação positiva" (ações afirmativas) na Europa, isto é, o reconhecimento e a abertura de inclusão social dos grupos identificados como maneira de correção das dívidas históricas causadas por preconceitos em todas suas formas.

Assim a questão da discriminação positiva é encaminhada como uma forma de promoção da "justiça social" historicamente situada, esquivando-se de outra leitura necessária a da noção de equidade necessária. O fato é que ao se colocar em discussão a equidade, pensou-se tão somente no seu caráter legal e instrumental, não se atentando convenientemente para a mudança estrutural da teoria social do capitalismo. O que observará nas proposições das políticas de ações afirmativas é que não se promove a equidade em seu sentido universal, mas se exclui grande contingente das ditas oportunidades sociais, gerando outras "injustiças históricas", o que ao se tornar cíclico esse processo, as medidas paliativas nunca terão fim.

Tais discriminações positivas tão profusamente defendidas no Brasil se originaram nos EUA para amenizar conflitos entre o movimento negro e o controvertido inimigo dos direitos civis - Nixon. Acrescente-se que a esse respeito vale lembrar Kaufmann (2009):

[...] percebe-se que uma das ironias sobre a criação das ações afirmativas é que estas foram imaginadas e colocadas em prática por alguns brancos que estavam no poder. Do contrário, os principais líderes do movimento negro organizado não se manifestaram favoravelmente a uma política integracionista, mas lutaram apenas para combater a discriminação institucionalizada. Martin Luther King chegou a se manifestar sobre o tema, advertindo que a adoção de políticas afirmativas seria contraproducente para o movimento negro, porque não conseguiria encontrar justificativas diante de tantos norte-americanos brancos pobres. 
Com efeito, nunca houve uma marcha para Washington em favor dessas medidas, nem mesmo pressão política consistente e relevante a favor de cotas ou de mecanismos de integração.

A questão colocada como "discriminação positiva" como medida de inclusão social, portanto, gera muito mais exclusão do grande contingente de expropriados, mas permanece como medida válida à medida que enreda os movimentos sociais na ilusão de inclusão social de fato, tomando o acesso à universidade como recorte. A construção de discursos e implementações legais de ações políticas neoliberais que preconizam a inevitabilidade de sua materialização constitui-se como parâmetro primordial dos aparelhos ideológicos das classes hegemônicas, em defesa da minimização do Estado e maior abertura e controle do mercado.

Isso não se dá sem o estabelecimento de lastros de conformação social por meio de ideologias e a sua veiculação pelos mass média, isto é, torna-se necessário a difusão e a preparação da sociedade para esse fim, um deles e o mais significativo é a inculcação acerca da morte das ideologias, onde a proclamação de um sentimento de pertinência e solidariedade pretende sobrepujar as diferenças de classes e as contradições entre dominadores e dominados, entre expropriadores e expropriados.

O reforço à solidarização, ao processo de integração pela humanização promovida pelo capitalismo tem se intensificado de tal maneira que, mesmo nos discursos de notáveis educadores universitários se faz sentir. $O$ pensamento universalizado é o da consensualidade em nome da melhoria de condições de vida e da desmobilização de movimentos de contestação contra o capitalismo metamorfoseado de humanização.

A mudança da percepção da realidade social atual como uma ideologia em sentido restrito na proposição da morte das ideologias, pois confere legitimação das propostas das classes hegemônicas e aceitação tácita dos indivíduos dogmatizados. As ações afirmativas têm a sua sustentação nesse âmbito paternalista: universidade para todos entendendo a parceria público-estatal como de interesse público, uma vez que atende parte da classe desfavorecida, quer por meio de cotas ou o mais comum, por meio de financiamento direto ou indireto subsidiado pelo Estado que se retira do atendimento pleno, visto que, os "nichos de excelência" são de competência dos "excelentes".

No caso brasileiro entre as unidades federativas, as primeiras a tornar obrigatórias as políticas de ações afirmativas foi o Rio de Janeiro, depois Mato Grosso seguido por Minas Gerais, a posteriori outras unidades federativas das demais regiões brasileiras também adotaram tais orientações. Silva (2006) destaca que os quadros interpretativos mundiais influenciam a discussão, adesão e implantação de políticas públicas em distintos âmbitos em que, cada país fará a sua justificativa, assim não há como não admitir que a reestruturação produtiva globalizada fosse elemento indutor de sua adoção no mundo. Portanto, o discurso da responsabilização social como meta humanizadora a partir de uma nova visão de mundo e do homem, primando pela superação das desigualdades sociais não apresenta qualquer sustentação.

No caso das ações afirmativas, as tipologias centradas na diversidade, capital humano, reparação e inclusão social apresentam justificativas e metas formais, "legitimadoras" de suas adesões por conta do perfil de justiça social defendido, como poderá se observar no quadro abaixo: 


\begin{tabular}{|c|c|c|c|c|}
\hline \multicolumn{5}{|c|}{$\begin{array}{c}\text { QUADRO } 1 \\
\text { TIPOLOGIAS DOS QUADROS }\end{array}$} \\
\hline QUADROS & DIVERSIDADE & CAPITAL HUMANO & REPARAÇÃO & INCLUSÃO SOCIAL \\
\hline JUSTIFICATIVA & $\begin{array}{c}\text { Estudantes de origens } \\
\text { diferentes devem ser } \\
\text { incluídos: } \\
\text { multiculturalismo }\end{array}$ & $\begin{array}{l}\text { Necessidade de } \\
\text { identificar talentos não } \\
\text { aproveitados por } \\
\text { deficiência do mercado } \\
\text { (market failure) }\end{array}$ & $\begin{array}{c}\text { Grupos étnicos } \\
\text { discriminados } \\
\text { historicamente devem } \\
\text { ser compensados. }\end{array}$ & $\begin{array}{l}\text { Grupos desfavorecidos } \\
\text { no presente devem } \\
\text { receber tratamento } \\
\text { especial. }\end{array}$ \\
\hline METAS FORMAIS & $\begin{array}{l}\text { Melhoria das relações } \\
\text { raciais e quebra de } \\
\text { estereótipos raciais }\end{array}$ & $\begin{array}{l}\text { Crescimento e } \\
\text { desenvolvimento } \\
\text { econômicos. }\end{array}$ & $\begin{array}{l}\text { Compensação e inclusão } \\
\text { social. }\end{array}$ & $\begin{array}{c}\text { Criação de } \\
\text { oportunidades para } \\
\text { mobilidade e inclusão } \\
\text { social. }\end{array}$ \\
\hline
\end{tabular}

Fonte: Silva (2006, p.141).

Segundo Silva (2006) a principal justificativa para a implantação das ações afirmativas no Brasil foi a oportunização de mobilidade de grupos desfavorecidos numa sociedade de alta desigualdade; assim, o ingresso à universidade pública seria um eixo de saneamento da mesma, o que começou com as cotas sociais para negros, estendendo-se aos demais grupos excluídos socialmente.

O controle social da hegemonia política do Brasil articulada aos interesses do capital internacional atesta que a primeira maior ameaça à democracia e ao desenvolvimento brasileiro é o baixo nível de escolaridade da população e a segunda é a pobreza e a desigualdade por conta das classes sociais. Ambas as variáveis são consideradas separadamente para efeitos de encontrar "um" ponto vilão para a não materialização da democracia, assim como separadamente são buscadas ações isoladas ou medidas paliativas para atenuar a busca pela universalização de direitos, no caso específico de acesso à universidade pública e gratuita.

Vale destacar que na Conferência das Nações Unidas contra o Racismo, em Durban, na África do Sul (31/08 a 07/09/ 2001), o Brasil se propôs a adotar políticas de ações afirmativas para garantir um maior acesso de afro-descentes à universidade pública. É um crasso reducionismo, pensar o caráter democrático e universalizante da universidade, pressupondo que as ações afirmativas garantiriam a implementação do direito à igualdade. Seria o mesmo que admitir que a igualdade fosse uma concessão e não um direito horizontalizado ou que alguns são mais iguais do que outros.

À luz do que já vinha acontecendo com outros países que aderiram aos pressupostos neoliberais, além dos países europeus que desde 1976, incorporara o conceito de "ação ou discriminação positiva", termo que vigoraria no "Programa de Ação para a Igualdade de Oportunidades da Comunidade Econômica Européia" em 1982 (momento da tessitura neoliberal encampada pelos EUA e Inglaterra), o Brasil na década de 1990 e mais contundentemente nos primeiros anos do século XXI é um signatário convicto de tais perspectivas.

Considerando o fundamento jurídico e normativo, Guimarães (1997, p.233), destaca que o objetivo das ações afirmativas ou discriminações positivas é o de promover privilégios de acesso a meios fundamentais educação e emprego, principalmente a minorias étnicas, raciais ou sexuais que, de outro modo, estariam deles excluídas, total ou parcialmente e o seu caráter temporário justifica-se pela hipótese da correção efetuada. Parece que dada como certa, uma vez que a própria lei estabelece o intervalo para "deliberação da igualdade", como se isso fosse mesmo possível, uma vez que conserva os 
mesmos arranjos de desigualdades sociais, modificando-se as ações do Estado no reconhecimento do direito e da igualdade.

A noção de "cotas" é um demonstrativo da ratificação de uma sociedade de classes, cujo metabolismo do capital, não prima por sua superação efetivamente, apenas anuncia uma preocupação nesse sentido, forja "iniciativas" nessa direção, mas que deixa sempre explícito qual a sua ênfase quanto à formação universitária desejada. Rodrigues (2007, p.45-47) afirma que a partir de 2004 a burguesia industrial, alargou os seus horizontes de participação na "modernização da universidade", pois encontrou a conjuntura política apropriada para isso.

A exemplo disso vale lembrar uma lista elaborada pela Confederação Nacional da Indústria (CNI), quando em 2004, foi convidada pelo então ministro da educação Tarso Genro, para participar de um debate sobre educação superior. Referindo-se à educação como o pilar do desenvolvimento econômico e pensando a educação superior a partir da acumulação capitalista, propôs um documento intitulado "Contribuição da Indústria para a Reforma da Educação Superior” em que seis grandes desafios foram listados:

1) Instituir novo marco regulatório para avaliar o desempenho das Instituições de Ensino Superior (IES).

2) Implementar um processo de autonomia substantiva no conjunto das universidades.

3) Desenvolver pesquisa básica e aplicada, cuja utilidade social e econômica esteja vinculada ao Projeto da Nação.

4) Aperfeiçoar os critérios de credenciamento e avaliação praticados pelo sistema de educação superior.

5) Implementar padrões educacionais compatíveis com a sociedade da informação e do conhecimento.

6) Ampliar a oferta de educação superior na área tecnológica.

É incrível que o mesmo documento que (CNI, 2004) afirma que a "[...] contribuição da indústria está acima de preconceitos e interesses particulares" (p.7), vai afirmar a necessidade de uma postura "pragmática" da educação superior no Brasil em que "[...] a universidade deve estar voltada para o setor produtivo e para o mercado de trabalho" e sugere que "[...] na avaliação popular, universidade e indústria são instâncias complementares" (p.13), por isso a justificação do ponto de vista do capital humano da defesa da universalização de oportunidades centradas numa igualdade controlada, participação e controle das instituições particulares que poderiam ofertar em tempo determinado melhor qualidade de ensino do que a oferta efetuada pelo governo, consoante a preparação das novas demandas populacionais para o mercado. Tal discurso reducionista orienta que para a superação das desigualdades basta o reconhecimento das mesmas e a criação de arranjos para a sua conformação, já que a indústria e a universidade são dimensões complementares.

O arranjo histórico de exclusão da oferta para o ensino superior não muda, pois a sua lógica, mediada por uma solidariedade do mercado, veicula um discurso com uma intencionalidade ainda velada, encampada entre defensores e contrários comedidos às políticas compensatórias que discursando a democratização e universalização ao ensino superior aos grupos marginalizados negam a sua efetiva materialização pelo consensualismo do modo-de-produção capitalista. 
Nenhuma medida que pretenda resolver ou atenuar parcialmente o acesso à universidade brasileira poderá ser promotora da justiça social, instrumento de libertação, humanização e universalização de oportunidades na dimensão mais simples de democracia. Isso porque a alternativa democrática entende a justiça sem parcialidades, entende a humanização como a ação transformadora do homem e no homem a partir de sua autoprodução e não exploração de sua força de trabalho e à medida que constrói a sua história, socializa de forma universalizada os bens culturais, políticos, econômicos e sociais.

A luta por uma universidade para todos no Brasil ainda é uma aspiração, entende-se que quando a imobilização social se justifica por concessões e rearranjos históricos das mesmas, há que levantar vozes em seu despertamento, porque a justiça social e os processos de não exclusão não são resultantes de medidas outorgadas, mas de conquistas. Por meio de uma contra-internalização provocada pela educação, por meio da emancipação concreta da sociedade e do homem e de suas formas de ser e estar no mundo poder-se-á reunir a dimensão necessária de libertação, justiça social, humanização e universalização das construções sociais. Nesse sentido, a universidade poderá responder efetivamente pela democratização e universalização em sua totalidade.

\section{Considerações finais}

O reconhecimento da igualdade pode prescrever o "quanto" tais demandas sociais podem ser ou ter? A mesma relação pode ser aplicada às discriminações positivas e, $a$ fortiori, de maneira muito mais cruel, pois pretende reforçar o discurso da igualdade e liberdade, delimitando, conformando e estabelecendo o percentual de reconhecimento dessa igualdade e liberdade e, portanto, da concessão de inclusão e ao mesmo tempo, eliminando de forma difusa as resistências ulteriores.

Quer em nível de ações afirmativas ou de discriminações positivas (como preferem os europeus), o quadro de exclusão social não se altera, muito pelo contrário, circunscreve quem pode e não ingressar na universidade na disposição dualista: mérito e concessão, por isso, “A defesa insincera da 'igualdade de oportunidades' associada à 'imparcialidade' e à 'justiça' serve a um objetivo apologético, pois, ao se eliminar a verdadeira igualdade, do rol das aspirações legítimas, as hierarquias estruturais do sistema do capital são reforçadas e se tornam provedoras indispensáveis das vazias 'oportunidades' prometidas e, ao mesmo tempo, são aclamadas por sua 'imparcialidade'”. (Mészáros, 2006, p.295).

A universidade tem sido objeto de distintas discussões, apresentando posicionamentos diversos, incluindo aqueles que insistem que o processo de expropriação histórica é mais cultural do que sócio-econômico, sem se ater na totalidade da relação capital-trabalho que efetivamente promove a manutenção da não-universalização, mesmo em face que um discurso que afirme o contrário. Qual o caminho? Recuperar o sentido entre direito, democracia, universalização e humanização como objetos inalienáveis da história e manifestações humanas que não se dará de forma gratuita ou naturalmente, mas por meio da manifestação do homem na história e com a história.

Nesse olhar, enquanto há enfrentamentos de fervorosos grupos sociais organizados na lógica da defesa ou não desse arranjo, não há porque alterar qualquer disposição de estrutura social que conduza à democratização da universidade no Brasil. Observa-se que o exercício da educação superior somente alcançará uma dimensão humanizadora, democrática e universal quando não se limitar à medidas paliativas, que se preocupam muito mais em esvaziar as vozes do que promover uma transformação social verdadeiramente qualitativa. 
A universidade numa dimensão universal, democrática e humanizadora, não aceita uma transformação negociada por medidas paliativas que pretendem em nome da "minimização de distorções sociais", conservar a mesma estrutura promotora do mercado humanizado e que mantém um discurso ambíguo em seu favor. A trajetória de uma universidade no âmbito da justiça social rompe com tal lógica, conferindo aos homens indistintamente, tornarem-se homens, pela superação das práticas dissimuladoras na centralidade capital-trabalho; pela ação comunicacional entre direito e democracia sem particularismos; pela leitura e encaminhamentos das problemáticas da educação e sociedade por meio da dialética do concreto e pelo esclarecimento que emancipa sem distorção de seu campo real e conceitual.

Não pode haver silenciamento em detrimento de qualquer mudança substancial que transforme o acesso à universidade em seu sentido mais profundo de libertação, humanização e universalização, articulando a mobilização pela superação da divisão social do trabalho e de classes, base estrutural da teoria social do neoliberalismo.

\section{Referências}

BRASIL. Grupo de Trabalho Interministerial para a Valorização da População Negra Brasília: Ministério da Justiça, 1996.

CONFEDERAÇÃO NACIONAL DA INDÚSTRIA. Contribuição da indústria para a reforma do ensino superior. Brasília: CNI/SESI/SENAI/IEL, 2004.

CONFERÊNCIA MUNDIAL SOBRE LA EDUCACIÓN SUPERIOR - Declaración mundial sobre la educación superior en el siglo XXI: visión y acción. UNESCO, Paris, 5-9 de outubro de 1998.

CONFERÊNCIA MUNDIAL SOBRE LA EDUCACIÓN SUPERIOR - La nueva dinâmica de La educación superior y La investigación para El cambio social y desarollo. UNESCO, Paris, 5-8 de Julio de 2009.

FILGUEIRAS, L. A. M. A desestruturação do mundo do trabalho e o "mal-estar" desse fim de século. In Cadernos do CEAS, N. 171, Setembro/Outubro 1997.

GUIMARÃES, A. S. A. A Desigualdade que anula a desigualdade: notas sobre a ação afirmativa no Brasil. In: SOUZA, J. (org.). Multiculturalismo e racismo: uma comparação Brasil- Estados Unidos. Brasília: Paralelo 15, 1997, p.233-242.

HOBSBAWN, E. J. Nações e nacionalismo desde 1780: programa, mito e realidade. Rio de Janeiro: Paz e Terra, 1991.

KAUFMANN, R. F. M. Ações afirmativas à brasileira: necessidade ou mito? A implementação para negros como mecanismo concretizador de direitos fundamentais. Uma análise histórico-jurídico-comparativa do negro nos Estados Unidos da América e no Brasil. Jus Navigandi, Teresina, ano 11, n. 1455, 26 jun. 2007. Disponível em: <http://jus2.uol.com.br/doutrina/texto.asp?id=10070>. Acesso em: 10 nov. 2009.

KURZ, R. O colapso da modernização. São Paulo: Paz e Terra, 1993. 
JESSOP, B. A globalização e o Estado nacional. Crítica Marxista, São Paulo, Xamã, v. 1, tomo 7, p. 9-45, 1998.

LIMA, P. G. Ações afirmativas como eixo ações afirmativas como eixo de inclusão de classes sociais menos favorecidas à universidade brasileira: um terceiro olhar entre pontos e contrapontos. Relatório de Pesquisa [Pós-Doutoramento]. Campinas/SP: Universidade Estadual de Campinas, 2009a.

LIMA, P. G. Política científica e tecnológica: países desenvolvidos, América Latina e Brasil. Dourados/MS: Editora da UFGD, 2009b.

LIMA, P. G. Unha de gato em novelo de lã ou do financiamento da pesquisa científica \& tecnológica no Brasil no governo Fernando Henrique Cardoso (1994-2002): o dito e o feito no "plano real". (Tese de Doutorado). Araraquara/SP: Universidade Estadual Paulista Julio de Mesquita Filho - FCLAR/UNESP, 2005.

MÉSZÁROS, I. Para além do capital. São Paulo: Boitempo Editorial, 2006.

PIOVESAN, F. Ordem jurídica e igualdade étnico-racial. São Paulo: Prol, 2006.

RODRIGUES, J. Os empresários e a educação superior. São Paulo: Autores Associados, 2007.

SILVA, G. M. D. da. Ações afirmativas no Brasil e na África do Sul. In Tempo Social, revista de sociologia da USP, v. 18, n. 2, 2006.

WEBER, M. The social psychology of the world religions . In: GERTH, H. \& MILLS, C. (eds.), From Max Weber. Nova York, Oxford University Press, 1946.

Notas: ${ }^{1}$ Docente do PPGEdu da Faculdade de Educação da Universidade Federal da Grande Dourados -UFGD.
Email: paulogl.lima@gmail.com

2 "Não as idéias, mas os interesses materiais e ideais governam diretamente a conduta do homem. Muito freqüentemente, as 'imagens do mundo' criadas pelas 'idéias' determinaram, qual manobreiros, os trilhos pelos quais a ação foi levada pela dinâmica do interesse” (Weber, 1946).

${ }^{3}$ Mészáros (2006b, p. 917) destaca que os componentes inseparavelmente entrelaçados do sistema orgânico do capital - em suas variedades capitalista e pós-capitalista - são: a) CAPITAL, representando não só as condições materiais alienadas de produção, mas, também - na qualidade de personificação dos imperativos materiais do capital, inclusive o imperativo-tempo (...) - a subjetividade que comanda e se opõe ao trabalho; b) TRABALHO, estruturalmente privado do controle das condições necessárias de produção, reproduzindo o capital em uma escala ampliada, ao mesmo tempo em que, como sujeito real da produção e personificação do trabalho, confronta defensivamente o capital; e c) ESTADO, como a estrutura global de comando político do sistema antagônico do capital que oferece a garantia final para a contenção dos antagonismos inconciliáveis e para a submissão do trabalho, já que o trabalho retém o poder potencialmente explosivo da resistência, apesar da compulsão econômica inigualável do sistema.

Recebido em: $\quad$ 15/04/11

Aprovado em: $\quad 12 / 10 / 11$ 